\title{
Dinâmica de inundação em áreas úmidas costeiras: zona urbana de Macapá e Santana, costa amazônica, Amapá ${ }^{1}$
}

\author{
Valdenira Ferreira Santos ${ }^{1}$ \\ 1 Geóloga, Dra. em Geologia e Geofísica Marinha pela Universidade Federal Fluminense-UFF. Pesquisadora do IEPA, Brasil. \\ E-mail: valdeniraferreira@gmail.com
}

\begin{abstract}
RESUM 0: As áreas úmidas representam cerca de um terço da área do Estado do Amapá. cujos processos de inundação ainda não foram devidamente esclarecidos e podem causar situações de calamidade pública, durante o período de chuvas, em áreas com adensamento populacional, gerando diversos riscos à população e danos socioeconômicos. Este trabalho apresenta o mapeamento das áreas úmidas nas áreas urbanas, nas cidades de Macapá e Santana, com o intuito de reconhecer a dinâmica de inundação e processos associados. As áreas e suas respectivas bacias hidrográficas foram mapeadas, aplicando critérios geomorfológicos utilizando um modelo digital de elevação superficial e um mosaico de imagens de sensores óticos de alta resolução. Trabalhos de campo foram realizados para identificar a rede de drenagem e suas nascentes e medir as variações no nível de água, em três pontos ao longo da bacia do Igarapé Fortaleza, nos períodos de máximos (março e maio) e mínimos (setembro e novembro) níveis d'água. As informações foram integradas em um Sistema de Informação Geográfica (SIG). Três conjuntos de áreas úmidas foram reconhecidas: os diques marginais, recobertos pelas florestas de várzeas; a planície de inundação com as áreas de pântanos, denominados localmente de "ressacas"; e um conjunto de canais de marés que bordejam a margem do rio Amazonas. Na planície de inundação, quinze sistemas de pântanos ("ressacas") foram mapeados. Os resultados podem contribuir para implementação de políticas para monitoramento e mitigação dos riscos à inundação em bacias hidrográficas costeiras, os quais se agravarão com o quadro de mudanças climáticas previsto para o futuro próximo.
\end{abstract}

Palavras-chave: inundação, áreas úmidas costeiras, costa amazônica, planejamento ambiental urbano.

\section{Flood dynamics in coastal wetlands: urban areas of Macapá and Santana, amazonian coast, Amapá}

ABSTRACT: Wetlands covered a third of State of Amapá whose flooding processes have not been properly studied. Such processes can lead to public calamity situation, especially in areas with concentration of populations. This paper presents the mapping of urban wetlands and their flooding dynamics associated, in the Macapá and Santana cities, near Amazonas mouth. Areas subject to flooding and their respective watershed were mapped applying geomorphological criteria using a digital elevation model of surface with interpretation of the morphological patterns in a mosaic of high-resolution imagery from of optical sensors. Fields work were conducted to mapping the drainage

${ }^{1} 0$ tema deste artigo foi divulgado em uma primeira versão, no apêndice do livro que trata do relatório final do projeto Zoneamento Ecológico-Econômico Urbano das Áreas de Ressacas de Macapá e Santana, Estado do Amapá (2012). 
network and its sources and the areas inundated by tides. The fieldwork research were made during the maximum ( $M$ arch to $M$ ay) and minimum (September to November) water level in the region. An Geographic Information System (GIS) were used to integrate all the information. Three sets of wetland areas were recognized: the levees covered by varzea forests; the floodplain, covered by marshes, and the areas with tidal channels occurring along of margin of Channel North. In the floodplain, were mapped fifteen marshes systems, known locally as "ressacas". The results allowed to classify the areas mapped as a system of coastal wetlands because of tide influence. For these areas should be developed strategies to monitoring and mitigate problems due the inundation, because the flooding risk will be intensified with climate change framework designed for the near future.

Keywords: flood, coastal wetlands, amazonian coast, urban environmental planning.

\section{INTRODUÇÃO}

As áreas úmidas incluem uma variedade de ambientes continentais (pântanos, terrenos turfosos, planícies de inundação, rios, lagos), costeiros (pântanos salinos, manguezais, recifes de corais e outras áreas marinhas localizadas a profundidades de até seis metros, em maré baixa), e artificiais (reservatórios e as bacias de tratamento de água). Tais áreas possuem uma política de conservação e uso sustentável, estabelecida na Convenção Ramsar (IUCN, 1971) que conta atualmente com 150 países signatários, incluindo o Brasil, que assinou a convenção em 1993.

Estas áreas cobrem $4 \%$ da superfície emersa da terra. A maioria delas localizadas em áreas tropicais e fazem parte das planícies de inundação dos rios. Nestas áreas, as condições ambientais de moderada a alta radiação solar, alta precipitação, alta temperatura, umidade relativa e 0 aporte regular de matéria orgânica, trazidas pelas inundações sazonais, criam um dos ecossistemas mais produtivos do mundo (M ITSCH, 1994; PRIGENT et al., 2001; M ARTINEZ; Le-TOAN, 2007).

Na Amazônia, as áreas úmidas estão distribuídas ao longo da planície de inundação da bacia do rio Amazonas em aproximadamente 1,77 milhão de $\mathrm{km}^{2}$ (HESS et al., 2003) e abrange as áreas de florestas de várzea, campos arbustivos, campos herbáceos e lagos (M ACIEL, 2001). Na região da foz do rio Amazonas, as áreas úmidas são influenciadas por pelas marés por grandes extensões, até a cidade de Óbidos, a $800 \mathrm{~km}$ do Oceano Atlântico, devido as características regionais peculiares como, por exemplo, o relevo plano e o regime de macromarés. De acordo com Santos (2006), o regime de marés e os processos climáticos globais e regionais regulam a dinâmica de inundação nessa região.

No estado do Amapá, as áreas úmidas estão distribuídas principalmente na

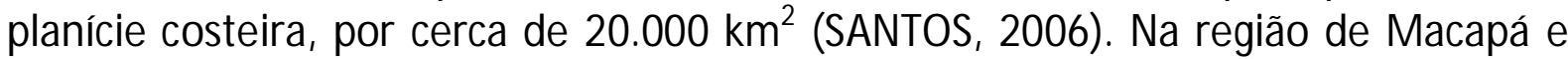
Santana, estão representadas pelas áreas de intermarés, florestas de várzeas e campos inundáveis (SANTOS et al., 2004). As áreas de campos inundáveis presentes zona urbana das cidades de Macapá e Santana, são denominadas popularmente de "ressacas" e são tombadas pela Lei Estadual no 0455/99. Esta lei impõe limitações ao 
uso e ocupação e determina claramente a necessidade de suporte técnico-científico para o melhor reconhecimento deste ambiente. Por outro lado, estas áreas úmidas, por constituírem terrenos inundados ou inundáveis, são áreas de riscos à população, principalmente em regiões densamente ocupadas.

Neste contexto, é importante reconhecer a amplitude, frequência e a distribuição dos processos responsáveis pela inundação, particularmente no contexto das bacias hidrográficas urbanas, como é o caso da Bacia do Igarapé Fortaleza.

Os resultados deste trabalho foram apresentados dentro de um levantamento exploratório realizado no âmbito do Projeto de Zoneamento Ecológico-Econômico Urbano (ZEEUR) das áreas de Ressacas de Macapá e Santana, Estado do Amapá (TAKIYAM A et al., 2012).

A área de estudo está localizada na Zona Urbano-Portuária do Setor Costeiro Estuarino do Estado do Amapá (SANTOS; FIGUEIRA, 2004) e envolve a bacia hidrográfica do Igarapé da Fortaleza e arredores, nos municípios costeiros de Macapá e Santana (Figura 1). 0 igarapé Fortaleza faz parte de uma microbacia homonômina que conecta-se com a margem esquerda do Canal do Norte do rio Amazonas, no Setor Costeiro Estuarino (op. cit.) e faz parte da Região Hidrográfica Amazônica (ANA, 2006).

Figura 1. Localização da área de estudo. A) Destaque para a planície costeira sul do Amapá, no setor costeiro estuarino, às margens do Canal do Norte. B) Áreas úmidas costeiras na zona ubana de Macapá e Santana e arredores.
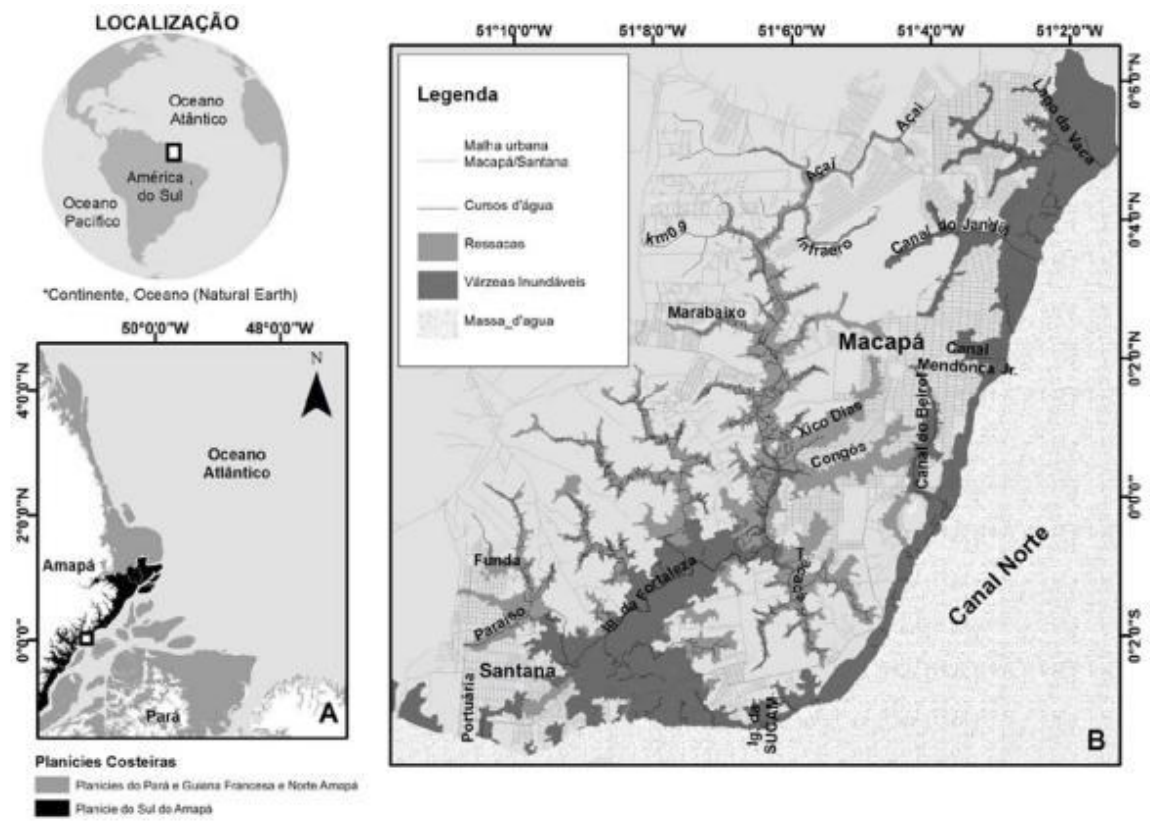

Adaptado a partir de Costa e Santos (2012); Pereira (2013); Santos et al., 2016.

O Setor Costeiro Estuarino faz parte da Planície Costeira Sul do Amapá. Nesta planicie se destacam as Planícies Fluvioestuarinas e Baixos Terraços do Rio Amazonas, cujo substrato é definido por formas acumulativas associadas as Planícies e Terraços 
Fluvioestuarinos Inundados pelas Marés (Apfet) e as Planícies Fluviais Inundáveis em Processo de Colmatação (Apfc) (SANTOS et al., 2004).

A unidade Apfet ocorre nas bordas do Canal do Norte do Rio Amazonas e nas margens das inúmeras drenagens que cortam a planície costeira; representam os depósitos de diques marginais mapeados por SANTOS et al., (2001) como Depósitos de Planície Flúvio-Estuarina 2 (Qfe2), constituídos por sedimentos pelíticos (silte e argila) que formam o substrato das florestas de várzeas.

A unidade Apfc corresponde aos Depósitos de Planícies Fluviais Antigas (Qfc) (SANTOS et al., 2001), constituídos por sedimentos argilosos e síltico-argilosos com sedimentos arenosos concentrados em paleofeições de meandros abandonados. De acordo com Santos et al. (2001) estes meandros estiveram bem ativos durante a última Transgressão Holocênica (cerca de 7.000 anos atrás) e suas planícies eram diretamente conectadas ao Amazonas e tiveram franca influência deste rio até aproximadamente 5.000 anos A.P. (cal). Com a descida do nível do mar, a sedimentação que deu origem ao atual substrato das florestas de várzea, fechou esses sistemas fluvias. Os pântanos foram formados, ocupando a paisagem, e originando os atuais campos inundáveis. Esta unidade teria começado a sua formação a aproximadamente 4.700 anos atrás, conforme datação registrada por Toledo e Bush (2008) na região do Curiaú.

Esses terrenos nos dias atuais são peridiodicamente inundados de acordo com o regime de cheias dos rios. Tais condições de inundação são regidas pelas variações bimodais no regime de precipitação devido com a presença da Zona de Convergência Intertropical (ZCIT). A influência de macromarés semidiurnas influenciam também na dinâmica de inundação (SANTOS, 2006).

Assim, a configuração da paisagem atual da região estudada, foi desenhada a partir da evolução de sistemas fluviais antigos, estruturados no passado geológico recente. Tal paisagem está condicionada pela dinâmica climatológica e oceanográfica a que estão submetidos os sistemas atuais.

\section{OS SISTEM AS FLUVIAIS E AS INUNDAÇÕES}

Os processos que vão influenciar na dinâmica de inundação em uma paisagem resultam da interação entre diversos fatores, os quais regulam o fluxo entre as águas superficiais e subterrâneas, dentro do ciclo hidrológico. Nesse ciclo, os rios principais e canais secundários tem um papel fundamental como área de captação do fluxo superficial e a área drenada por este fluxo depende, da área da bacia hidrográfica, do relevo, da forma dos canais, e dos processos que regulam o fluxo hídrico.

Esses processos estão intrinsecamente relacionados com a dinâmica climática, e no caso das áreas costeiras, somam-se os processos oceanográficos. Entender os conceitos e características ambientais dos elementos que canalizam o fluxo hídrico, como a rede drenagem, canal fluvial e canal de maré, é fundamental para entender 0 
funcionamento da dinâmica de inundação e auxiliar no processo de planejamento ambiental e territorial.

\subsection{Os Sistemas Fluviais, as Bacias Hidrográficas e os Canais de Maré}

Idealmente, o sistema fluvial consiste de uma área fonte de sedimento, uma rede de transporte e um local de deposição desse sedimento (SCHUM, 2003). Em um sistema fluvial é necessário existir nascentes que derivem a rede de drenagem que transportará águas e sedimentos rio abaixo em direção a sua foz. Dois grandes subsistemas podem ser identificados no sistema fluvial: o canal fluvial e a planície de inundação.

O canal fluvial recebe toda a carga de água e sedimentos que são constantemente transportados ou depositados ao longo do rio, gerando uma série de barras. Este canal tem sua dinâmica controlada pelos regimes climáticos. Nos períodos chuvosos as águas podem transbordar para fora do canal e neste transbordamento geram depósitos das margens de canais que são os diques marginais, representados na área de estudo pelas florestas de várzea que bordejam o Canal do Norte do Rio Amazonas. As águas, ao transbordarem para fora do canal alagam as áreas adjacentes das planícies de inundação, as quais são geralmente mais baixas que os diques marginais. As planícies de inundação são os assoalhos dos vales construídos por rios ativos, periodicamente recobertas por águas da inundação durante os períodos de fluxos das cheias dos rios e que ultrapassam os diques marginais (BAKER, 2009).

Ao fenômeno de aumento do nível das águas dos rios, sem ultrapassar a margem dos diques marginais, dá-se o nome de enchente. Em algum momento, dependendo da geometria do canal e da precipitação, o rio excede a altura dos diques marginais e gera um fluxo que transborda para fora das margens do canal (BLOOM, 2004), portanto, para dentro das planícies de inundação. Assim, a inundação é um fenômeno natural associado a dinâmica de cheias dos sistemas fluviais quando a precipitação é intensa e a quantidade de água que chega é superior a sua capacidade de drenagem, inundando as áreas adjacentes às margens do canal. Estas áreas são geralmente ocupadas por populações devido ao seu potencial de uso. Se densamente ocupadas, esta situação pode assumir dimensões catastróficas denotando a importância do planejamento e a necessidade de compatibilização do uso do solo (TUCCI 2004).

A existência de um sistema fluvial resulta na formação de uma bacia hidrográfica. O sistema fluvial constitui, conceitualmente, um ambiente onde dominam os processos de erosão, transporte e deposição realizado pelos rios (COLLISON, 2012). A bacia hidrográfica é o elemento fundamental de análise da fase terrestre do ciclo hidrológico, sendo formada por área de captação natural da água de precipitação que faz convergir os escoamentos para um único ponto de saída, seu exutório. É composta por um conjunto de superfícies vertentes e de uma rede de drenagem 
formada por cursos de água que confluem até resultar em um leito único no seu exutório (SILVEIRA, 2004). A bacia hidrográfica é a unidade ambiental que melhor garante a integração dos sistemas ecológicos, sendo utilizada para a implementação da política de recursos hídricos de acordo com a Lei n. 9.433, de 8 de janeiro de 1997. Portanto, é considerada como uma unidade de planejamento ambiental no Brasil.

A conformação da bacia hidrográfica, depende, entre outros fatores, da forma e arranjo da rede de drenagem. Esta rede de drenagem compõem os diversos cursos de água em uma bacia hidrográfica e consiste de vales e caminhos de seus canais organizados em um sistema de conexão. Para a rede de drenagem, em uma bacia, convergem água e sedimentos que são regulados pelos controles climáticos, geológicos, geomorfológicos, pedológicos e pela vegetação (BAKER, 2009).

A rede de drenagem, junto com os interflúvios, formam a bacia de drenagem. Porém nem toda bacia de drenagem forma uma bacia hidrográfica com rios e suas nascentes. É comum, nas áreas costeiras, a presença de canais de maré que podem formar uma intrincada rede de drenagem. De acordo com Perillo (2009) a diferença principal é que nos rios o fluxo é unidirecional e nos canais de marés os fluxos são bidirecionais, forçados pelas marés, e geralmente estes canais são elaborados exclusivamente dentro de áreas úmidas sujeitas a inundação por marés.

Nas bacias hidrográficas costeiras somam-se dois regimes de inundação dentros dos sistemas fluviais: um influenciado pelos processos climáticos e outro, pelos processos oceanográficos, neste caso as marés. Por outro lado, os canais de marés, por mais intrincada que seja a sua rede de drenagem não devem ser considerados como bacias hidrográficas, pois contradizem os conceitos acima apresentados.

Entender as características e as relações entre a rede drenagem, bacia hidrográfica, canais fluviais e canais de marés é fundamental para entender os processos sistêmicos, incluindo a dinâmica de inundação e auxiliar no processo de planejamento ambiental.

\subsection{Dinâmica de Inundação nas Áreas Úmidas Costeiras Amazônicas}

A variação do nível de água em um rio depende das características climatológicas e físicas da bacia hidrográfica. A distribuição temporal e espacial da precipitação é a principal condição climatológica e pode ser prevista com antecedência (TUCCl, 2004). Nas bacias hidrográficas costeiras, as marés também fazem variar o nível de água, resultando na formação, ou de estuários, ou de deltas. Esta variação do nível de água em função das marés também é um fenômeno que pode ser previsto a partir do monitoramento costeiro.

Nas áreas úmidas costeiras amazônicas a variação do nível de água dos rios depende das variações sazonal e interanual na precipitação regidas por fatores climáticos globais, como a presença da Zona de Convergência Intertropical (ZCIT) e do El-Niño-Southern Oscillation (ENSO). A variação da ZCIT regula o regime de 
precipitação definindo os dois períodos sazonais bem marcantes na região equatorial: um de alta precipitação e outro de baixa precipitação, definindo um sistema bimodal. Estes regimes são influenciados pelos fenômenos ENSO que causam variações interanuais até decenais na precipitação, influenciam os rios tropicais (LATRUBESSE; STEVAUX; SINHA, 2005), incluindo o rio Amazonas (RICHEY; NOBRE; DESER, 1989), e afetam ainda os regimes hidrológicos (SANTOS et al., 2010), afetando, portanto, as cotas dos rios na costa amazônica. Assim, sazonalmente ocorrem as cheias e secas que podem ter sua intensidade aumentada ou diminuida em função dos eventos globais.

As marés são ondas de longo período que se originam e movem-se através dos oceanos e são geradas em resposta as forças exercidas pela Lua e Sol sobre o Planeta. Elas progridem em direção a linha de costa com contínua subida e descida do nível superficial do mar. A maré alta (preamar) ocorre quando a parte mais alta de crista da onda de maré alcança um determinado local; a maré baixa (baixamar), corresponde a calha da crista dessa onda. A diferença na altura entre a preamar e a baixamar é chamada de amplitude de maré (ROSS, 1995).

Como o regime de marés sofre influência astronômica e gravimétrica, os períodos de inundação das áreas úmidas costeiras amazônicas são determinados por essas variações no arranjo do sistema Sol-Lua-Terra. Assim, as maiores amplitudes de marés serão encontrados nos períodos de sizígias, principalmente durante os equinócios de março e setembro. Nesses períodos ocorrem as marés mais altas e também as marés mais baixas, ocasionando, assim, maior exposição das zonas de intermarés durante a baixamar, ou maior imersão dos ambientes, durante a preamar.

$\mathrm{Na}$ planície costeira amapaense, as marés possuem características semidiurnas, têm grandes amplitudes (meso, macro a hipermarés) e o relevo local é muito baixo e plano; assim, extensas áreas ficarão inundadas e descobertas duas vezes por dia (SANTOS, 2006).

Os eventos de inundação associados aos fenômenos acima se somam ou se anulam. Portanto, é de se esperar, que a maior inundação seja encontrada durante os períodos de cheias dos rios (março a maio) e equinócios. A condição de mínimo nível de água será atingida pela maior amplitude de maré nas sizígias de equinócio (setembro) e no período de menor nível de água dos rios (setembro a novembro), quando extensas zonas de terra podem ficar expostas.

As interações entre o regime pluviométrico e as marés na zona costeira também é encontrado em outros locais na costa amazônica, a exemplo da Guiana Francesa, cujo fenômeno foi estudado por Lointier (1996), um dos poucos trabalhos que traçaram 0 hidroperíodo nessa região costeira.

A superposição entre os fenômenos descritos acima são nitidamente observados nas curvas de vazões em estações fluviométricas na Amazônia com influência das marés, a exemplo de Óbidos (Figura 2A), e nos maregramas das estações costeiras, a exemplo de medições realizadas na foz do Amazonas (Figura 2B). Estes cenários 
integrando a influência fluvial e processos costeiros podem ser previstos e foram descritos por Almeida (2008). Tais cenários tornam complexos os estudos ambientais no que tange aos riscos costeiros, sejam eles naturais ou antropogênicos.

Variações interanuais de ocorrência dos fenômenos de El Niño e La Niña influenciam nestes cenários de inundação e resultariam em períodos propícios para as grandes cheias e secas na região; tais influências na região costeira amapaense, foram confirmadas por (SANTOS et al., 2010). Por outro lado, ciclos de maré de longo período (18,6 anos) também podem contribuir para o aumento do nível de inundação, talvez mais que as mudanças relativas no nível relativo do mar, de acordo com Gratiot et al., (2008) que conseguiram definir essa ciclicidade para a costa da Guiana Francesa.

Vale ressaltar, que no cenário de mudanças do nível do mar, está previsto um contínuo aumento da elevação do nível médio global do mar projetando um aumento de 0,26 a 0,55 $\mathrm{m}$ até os anos de 2081-2100 (IPCC, 2013). Desta forma, considerando as áreas costeiras de relevo muito plano e em cotas baixas, como é o caso das áreas na foz do Amazonas, deve-se estar preparado para esse cenário de mudanças.

Assim, 0 entendimento desses processos e de suas repercussões sobre os ecossistemas, o uso dos recursos, bem como sobre a ocupação das áreas costeiras, não deveria ser colocado como segundo plano, nas estratégias de planejamento e uso do território. Pois são nas zonas costeiras que concentram-se o maior contigente populacional do planeta.

Figura 2: llustrações das variações do nível de água ao longo do rio Amazonas revelando a superposição do regime de marés e fluvial nos processos de inundação da planície amazônica. (A) Cotas máximas diárias do rio Amazonas em Óbidos e (B) variações no regime de marés na foz do rio Amazonas (estação da ilha do Brigue).
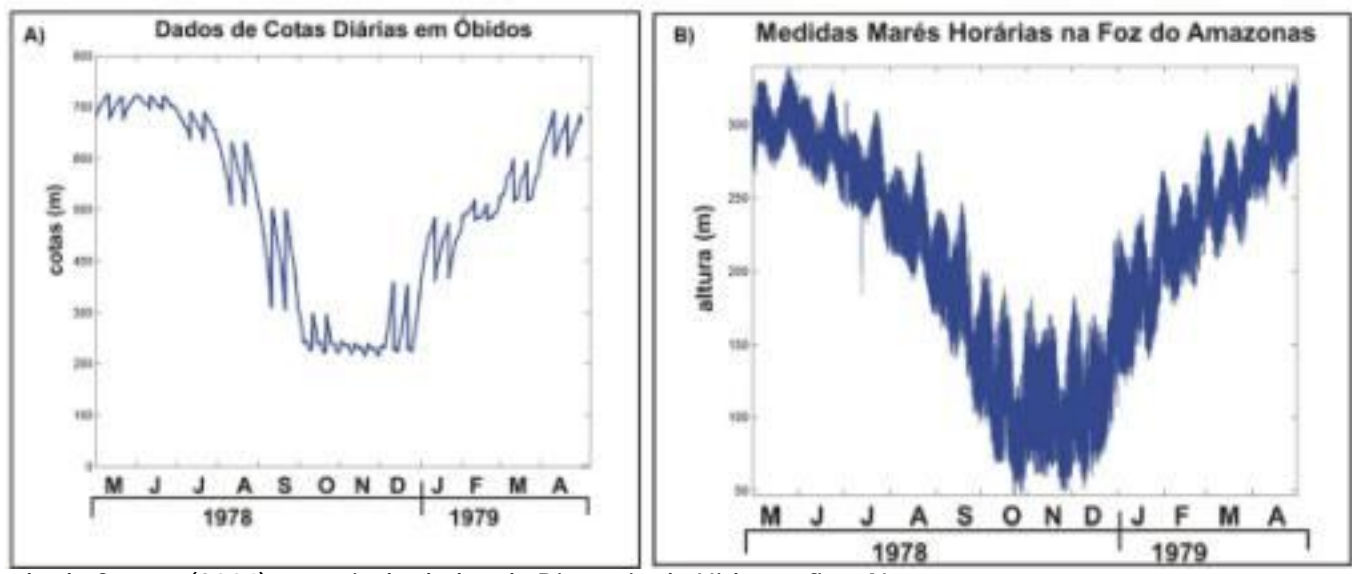

M odificado de Santos (2006) a partir de dados da Diretoria de Hidrografia e Navegação.

\section{MAPEAM ENTO DAS ÁREAS ÚMIDAS COSTEIRAS}

A abordagem da temática de inundação foi realizada de forma exploratória com interpretação de um mosaico de imagens de alta resolução que constituíram uma base cartográfica em escala 1:10.000, aliado a coleta de dados de campo realizados 
durante os períodos de máxima (março e maio/2010) e mínimo (setembro e novembro, 2009) de inundação na região.

\subsection{Geração da Base Cartográfica}

A base cartográfica foi construída a partir de um conjunto de imagens de alta resolução ortorretificadas utilizando um modelo de elevação digital (MDE) e dados de controle de controle de campo. 0 sistema de referencia espacial adotado foi 0 Sistema de projeção UTM , zona 22 Sul com Datum horizontal WGS 1984.

O MDE foi utilizado para mapeamento das macrofeições geomorfológicas e assim auxiliar na fotointerpretação dos limites das bacias hidrográficas e quebras de relevo, como também para o processo de ortorretificação das imagens de alta resolução. Estes dados foram utilizados devido à ausência de modelos detalhados adequados que recobrissem toda a área do projeto na época do trabalho. 0 dado foi obtido pela Shuttle Radar Topography Mission (SRTM), entre 11 e 22 de fevereiro de 2000, durante a missão STS-99 da espaçonave Space Shuttle Endeavor (RABUS et al., 2003) e 0 modelo gerado através da técnica de interferometria InSAR -Interferometric Synthetic Aperture Radar, com dados coletados em bandas C e X (curtos comprimentos de ondas). Os dados foram adquiridos originalmente com espaçamento do grid de 1 arco segundo (aproximadamente 30 metros) e na época eram distribuídos gratuitamente pela NASA na forma de DEMs (digital elevation models), em áreas de $1^{\circ} \times 1^{\circ}$, com resolução de 3 arcos segundo (aproximadamente 90 metros) para regiões fora dos USA. Os dados SRTM foram classificados em intervalos de 1 (um) metro de amplitude visando realce de informações da amplitude do relevo e assim melhor definir as zonas inundáveis.

As imagens de alta resolução foram adquiridas pelo projeto ZEEUR e utilizadas na confecção do mosaico. 0 mosaico foi composto por um conjunto de cinco imagens óticas dos satélites GeoEye e QuickBird, do ano de 2009, ortorretificadas a partir do DEM SRTM e utilizando a função Rational Polynomial Coefficients (RPC). Para melhorar a acurácia do posicionamento foram adicionados a cada cena cerca de quatro pontos de controle de campo (Ground Control Points-GCP). Os GCPs foram coletados em abril e maio de 2011 considerando um grid da área, em escala 1:10.000. A coleta dos pontos foi realizada com GPS Geodésico, em modo estático, com tempo de rastreio de aproximadamente 30 minutos, em cada ponto, e com taxa de recepção do sinal de satélites de 3 segundos. Para o processamento dos pontos foi utilizada a estação M APA da Rede Brasileira de M onitoramento Contínuo, localizada em Macapá. No total, foram coletados 32 pontos, dos quais 17 foram utilizados para a correção geométrica das cinco cenas de imagens de alta resolução e 15 pontos foram utilizados como pontos independentes para a averiguação da qualidade do registro.

A avaliação da qualidade do mosaico foi aferida através do Programa livre GeoPEC (SANTOS, 2010) e o Padrão de Exatidão Cartográfica (PEC) calculado forneceu a 
Classe A para uso planimétrico do mosaico com erro médio quadrático de $1,53 \mathrm{~m}$. A avaliação de altimetria não foi realizada em virtude dos erros inerentes aos dados SRTM para a escala de trabalho.

\subsection{Mapeamento da Rede de Drenagem e Delimitação da Bacia do Igarapé Fortaleza}

A extração da rede de drenagem foi realizada a partir de levantamentos, em campo, dos cursos de águas e suas nascentes e a partir do método de fotointerpretação sobre o mosaico base. Os levantamentos de campo tiveram como objetivo identificar os caminhos dos canais e a influência máxima das marés. 0 levantamento das nascentes teve como objetivo dirimir dúvidas sobre o limite da bacia hidrográfica do Igarapé Fortaleza, bem como mapear o afloramento do nível de água do lençol freático.

Para a bacia do Igarapé Fortaleza, o mapeamento dos cursos de água foi realizado no período chuvoso (março e abril de 2010) e no período de transição para a estação de menor precipitação na região (julho e agosto de 2009). Estes períodos foram escolhidos para facilitar o acesso aos canais, visto que no período seco, alguns não são navegáveis. 0 mapeamento das nascentes foi executado considerando os dois períodos sazonais (dezembro/2009 e março/2010) e foi realizado a partir de pontos previamente reconhecidos sobre 0 mosaico base, cujas coordenadas foram inseridas no GPS de navegação.

Para os canais da orla de Macapá e Santana, em virtude da facilidade de acesso e visando observá-los em situação de baixo nível de água dos rios e sob influência das marés sizígia, o levantamento foi realizado no período seco (outubro e novembro de 2010).

O mapeamento dos cursos de água e das nascentes foi realizado com um GPS de navegação com a gravação em tempo real das trilhas e de pontos de controle. Os cursos de água mapeados foram espacializadas sobre o mosaico base e aqueles que não puderam ser acessados em campo, foram mapeados a partir de método de fotointerpretação.

O limite da bacia do igarapé Fortaleza foi extraído de forma manual a partir da rede de drenagem mapeada e das informações de elevação provenientes do MDE. 0 critério adotado para a vetorização foi o de máxima amplitude dos interflúvios, para os dados de elevação, e para a fotointerpretação do mosaico, foram considerados os padrões das formas de relevo. Ressalta-se que, apesar das limitações dos dados SRTM, em virtude da resolução da célula do DEM (90 metros), foi possível identificar as estruturas de relevo da área. 0 padrão da floresta de várzea confundiu-se com as áreas de cobertura vegetal densa existente nas bordas da terra firme. Estas ambiguidades foram esclarecidas através da validação das informações em campo. 


\subsection{Mapeamento das Áreas Susceptíveis a Inundação}

O mapeamento foi executado considerando os critérios de fotointerpretação apresentados por Soares e Fiori (1976): presença de quebra de relevo, situação de umidade no terreno e forma dos vales. Os padrões da cobertura vegetal nas imagens (forma, cor, tonalidade, textura) também foram utilizados como critério para definir os limites das áreas susceptíveis a inundação.

Os limites identificados foram digitalizados sobre 0 mosaico base. $\mathrm{Na}$ impossibilidade de identificação clara dos limites, devido a presença de nuvens ou ocupação, foram utilizadas como auxílio imagens de alta resolução do satélite IKONOS, do ano de 2001.

A escolha da vetorização de forma manual se deve principalmente a complexa e heterogênea resposta espectral dos ambientes naturais em áreas urbanas, em imagens de alta resolução, que restringem o uso de uma classificação automática.

A validação dos padrões definidos a partir da fotointerpretação foi realizada utilizando os dados levantados in situ e as fotografias aéreas provenientes de dois sobrevoos realizados em novembro de 2009. As rotas dos sobrevoos foram previamente planejadas sobre as imagens de satélite e registradas com o auxílio de um GPS de navegação. As fotografias aéreas foram tomadas com uma câmera digital, cujo relógio da câmera digital foi sincronizado com o relógio do GPS. Isto permitiu a geolocalização das fotografias aéreas nas imagens e a espacialização das rotas e registros fotográficos sobre o mosaico.

\subsection{Reconhecimento dos Processos de Inundação}

Para identificar a área de influência das marés, foram realizados quatro levantamentos em campo, considerando os ciclos de máximas e mínimas alturas de marés (períodos de equinócios em situação de sizígia - março/2010 e setembro/2009) e as condições de máxima e mínima descarga líquida do rio Amazonas, em situação de sizígia (maio/2010 e novembro/2009). Estes critérios de datas permitem reconhecer os limites máximos e mínimos dos níveis de água na área de estudo.

Os locais de observação e leitura do nível da maré foram definidos a partir da aplicação de 11 questionários semi-estruturados (Figura 3) aos moradores com mais de um ano de residência ao longo do igarapé Fortaleza. Os questionários foram aplicados a partir de $2 \mathrm{~km}$ em direção a montante do curso do Igarapé Fortaleza e possuíam perguntas objetivas relacionadas com a ocorrência e as variações das marés na área. $A$ partir desses resultados, foram escolhidos três pontos de medições (M 01, M 02 e M 03), que representassem diferentes situações de influência das marés. 
Figura 3. Distribuição da rede de drenagem mapeada e resultados das medições do nível de água na bacia hidrográfica do igarapé Fortaleza. A) Mapa com os limites das bacias hidrográficas, rede de drenagem, pontos de medições das marés e local de aplicação dos questionários. Ao lado direito, os valores de nível de água medidos. B) Variações do nível de água no ponto M 01, Lagoa dos Índios. C) Resultados das medições realizadas no ponto M 02. D) Variações do nível de água no ponto M 03, foz do Igarapé Fortaleza.
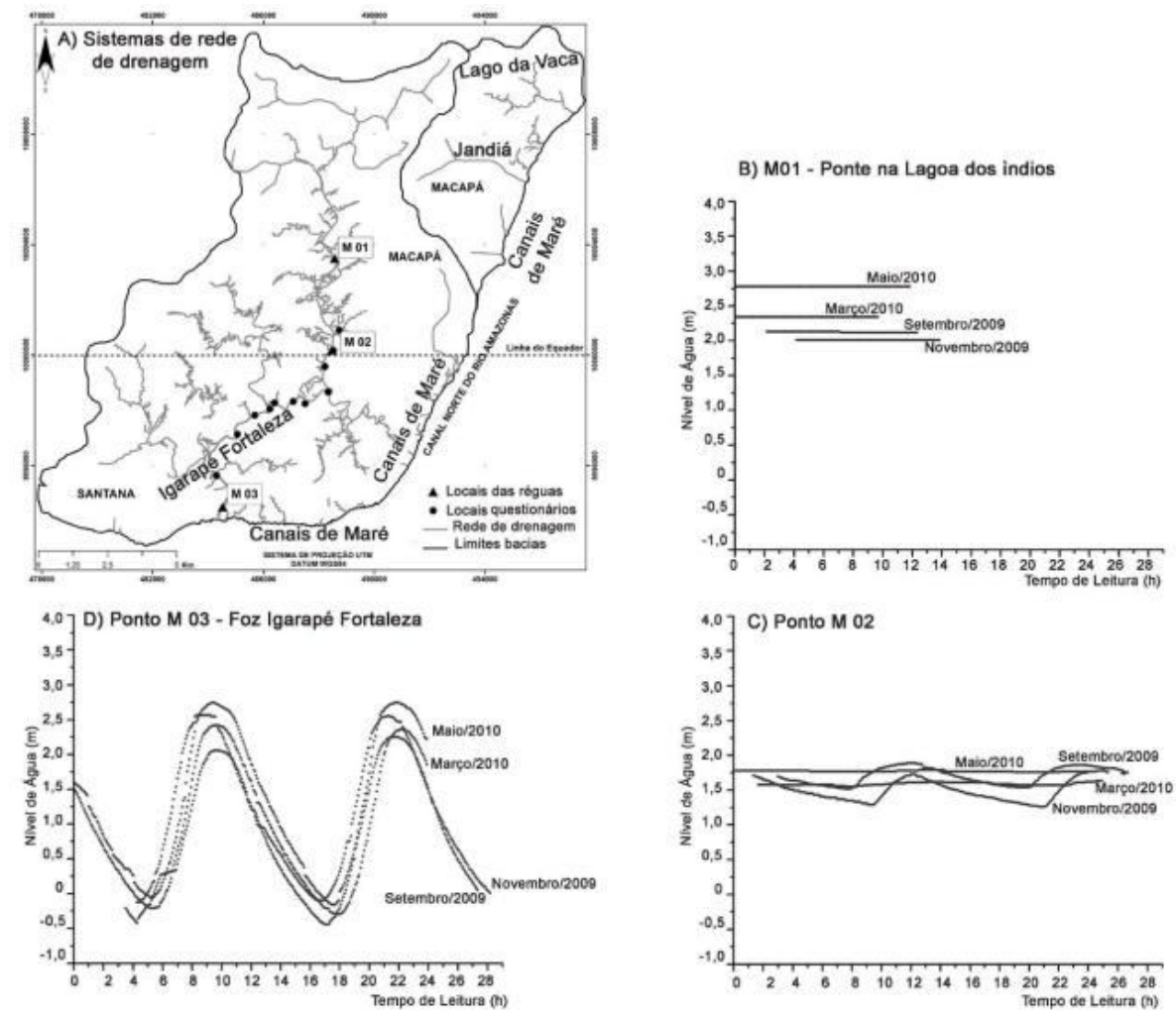

Fonte: M odificado de Costa e Santos (2012).

A altura do nível de água foi aferida com réguas limnimétricas graduadas a cada centímetro, com leitura a cada 5 minutos. A leitura das réguas foram realizadas de forma sincronizada entre as equipes de campo e o tempo de leitura foi de no mínimo 24 horas para os locais de influência de marés e de 12 horas para locais sem influência de marés.

0 zero absoluto das réguas foram determinados a partir de marcos geodésicos instalados às proximidades das réguas, cujas coordenadas ( $x, y$ e $z$ ) foram definidas a partir do rastreio com GPS geodésico. 0 tempo de rastreio foi de quatro horas para cada marco implantado. As altitudes elipsoidais foram determinadas a partir do método de triangulação utilizando as estações da Rede Brasileira de Monitoramento Contínuo (RBMC) MAPA e APSA. As altitudes ortométricas foram determinadas utilizando o Programa M APGEO (IBGE, 2004). A correlação entre as alturas do nível de água medido nas réguas foi estabelecida a partir do nivelamento geométrico entre os marcos geodésicos (com suas altitudes ortométricas) e o zero absoluto das réguas.

Os dados foram planilhados e os gráficos elaborados, correlacionando-se o início de leitura entre os pontos. Nas áreas onde não foi possível medir a influência das 
marés a partir de réguas, foram realizadas visitas de campo no período de máxima inundação em situação de sizígia.

Desta forma foi possível estabelecer as áreas com influência de marés dentro da planície de inundação.

\subsection{Construção do Mapa de Dinâmica de Inundação}

O mapa de dinâmica de inundação foi construído a partir do cruzamento espacial do mapa de unidades morfológicas das áreas úmidas mapeadas (planície colmatada e diques marginais) com a distribuição dos pontos onde foram reconhecidos a influência das marés no período de máximo e menor nível de inundação. As classes de inundação adotadas neste trabalho foram determinadas a partir do trabalho de Martinez e Le-Toan (2007) com adaptações. Estes autores definiram três classes de sistemas inundados na planície amazônica, a partir de imagens de radar, considerando as condições de permanência da inundação: nunca inundado, ocasionalmente inundado e permanentemente inundado. Neste trabalho foi adotado 0 critério de influência dos processos de inundação, definindo-se três classes: não inundado, inundado pelas águas pluviais, inundado pelas águas pluviais e pelas marés.

\section{OS SISTEM AS DE REDE DE DRENAGEM E AS BACIAS HIDROGRÁFICAS DO IGARAPÉ DA FORTALEZA (MACAPÁ - AP)}

Os resultados permitiram mapear três conjuntos de rede de drenagem (Figura 3): a) a rede de drenagem associada a bacia hidrográfica do igarapé Fortaleza; b) as redes de drenagens associadas ao canal do Jandiá e igarapé do Lago da Vaca; e c) redes de drenagens dos pequenos canais na orla de Macapá e Santana.

A rede de drenagem da bacia hidrográfica do Igarapé Fortaleza está distribuída em uma área de aproximadamente $169 \mathrm{~km}^{2}$ e possui forma dendrítica, o que implica dizer que é uma rede elaborada sobre terrenos sedimentares. 0 canal principal é meandrante e possui aproximadamente $25 \mathrm{~km}$ de extensão conectando-se diretamente com o Canal Norte do rio Amazonas. Para este canal confluem drenagens de menor expressão que nascem geralmente na borda do cerrado, alimentando as matas de galerias, e percorrem os sistemas de áreas úmidas deprimidas (ressacas), localizadas atrás dos diques marginais. Dentro dos sistemas de ressacas o canal principal é meandrante, desaparecendo por vezes dentro da planície colmatada. Estes canais possuem uma importância vital no período menos chuvoso por serem as áreas mais úmidas dentro dessa planície.

As nascentes dos cursos de água que compõem essa rede de drenagem são do tipo intermitente, associadas aos rios de primeira ordem (M AGALHÃES; SANTOS, 2010), com água brotando do solo apenas nos períodos chuvosos devido a baixa 
profundidade do lençol freático. Das 41 nascentes identificadas em campo, a maioria encontra-se com a vegetação parcialmente suprimida. Nas áreas urbanas, são comuns os aterramentos dessas nascentes que podem futuramente comprometer 0 suprimento de água para a bacia a partir do lençol freático e ameaçar 0 funcionamento do sistema.

A rede de drenagem do Canal do Jandiá e Lago da Vaca está distribuída em uma área de $33,17 \mathrm{~km}^{2}$. Estes sistemas de redes de drenagem foram mapeados anteriormente como componentes da bacia hidrográfica do igarapé da Fortaleza. Porém, os resultados deste mapeamento indicam tratar-se de sistemas de drenagens independentes, cujos interflúvios são bem definidos nos dados de sensores remotos. 0 padrão e forma de ocorrência da rede associada a estes sistemas indicam tratar-se de canais de maré e não de rios e portanto não devem ser considerados conceitualmente como bacias hidrográficas.

A rede de drenagem relacionada aos igarapés que ocorrem ao longo da orla de Macapá e Santana possui direção perpendicular à linha de costa e drenam as áreas de florestas de várzeas do rio Amazonas (Figura 3A). Alguns desses canais podem ter sua gênese associada a canais de marés, cujas relações precisam ser melhor averiguadas. Apesar de suas pequenas dimensões, são canais importantes para alimentação dos ecossistemas de várzea que ainda persistem dentro da zona urbana de Macapá e Santana e que deveriam ser preservados, por sua função ecológica na renovação das águas e nutrientes e na contenção dos processos erosivos.

\subsection{Os Sistemas de Áreas Úmidas}

Dois grandes sistemas de áreas úmidas foram mapeados na região: um sistema associado aos diques marginais do igarapé Fortaleza e o sistema da planície de inundação. Sistemas menores de áreas úmidas com características de planície de inundação fazem parte da drenagem do Canal de Jandiá e Lago da Vaca. Além desses sistemas, drenam a orla das cidades de Macapá e Santana, uma série de pequenos canais (Figura 3) que cortam os diques marginais do Canal Norte do rio Amazonas. Estes sistemas fazem parte do leito maior de inundação do Canal Norte. Durante a época de cheias dos rios (março a maio) todos esses sistemas se interligam e a maior parte deles é influenciado pelas marés (Figura 4).

No sistema de diques marginais desenvolveram-se as florestas de várzea (no igarapé Fortaleza e no Canal Norte do rio Amazonas). No sistema da planície de inundação desenvolveram-se os pântanos e fazem parte dos campos inundáveis (popularmente denominados de ressacas). Estes sistemas por se conectarem com 0 canal principal do igarapé Fortaleza, que possui influência das marés, também são influenciados diariamente pelas águas das marés, especialmente os que estão mais próximos do Canal do Norte do Rio Amazonas. As margens mais elevadas recebem a 
influência das marés de sizígia, sendo, portanto, inundadas, no mínimo duas vezes por mês, durante os perío dos de sizígia.

Figura 4. Sistemas de áreas úmidas costeiras na zona urbana de Macapá e Santana associados as "ressacas".

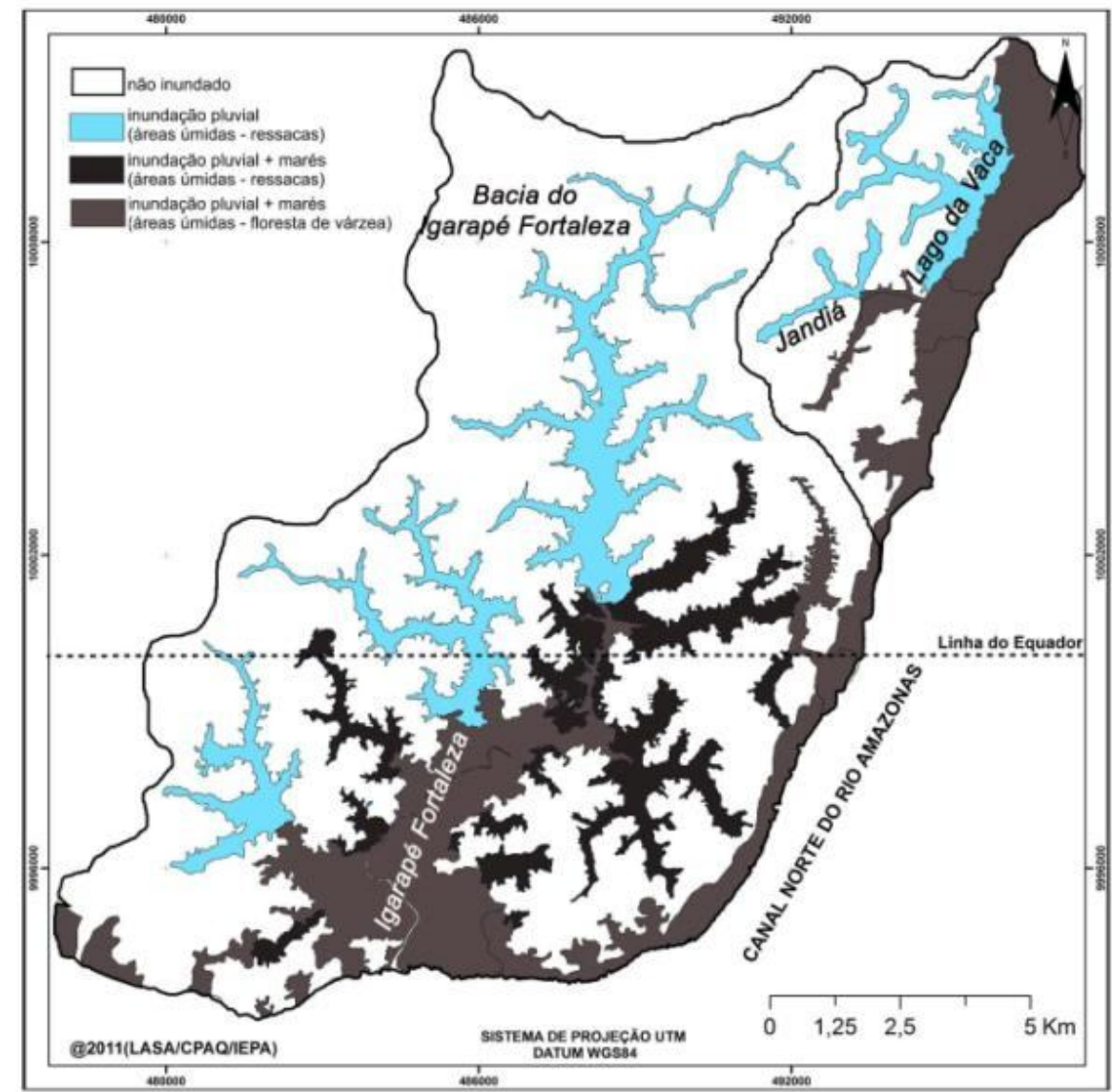

Fonte: Modificado de Costa e Santos(2012).

Na planície de inundação da bacia do igarapé Fortaleza foram identificados 15 subsistemas de "ressacas" distribuídos em uma área de $28,94 \mathrm{~km}^{2}$, que representa $17,11 \%$ da bacia hidrográfica (Figura 3). Eles estão distribuídos tanto na margem esquerda, quanto na margem direita do canal principal atrás das áreas dos diques marginais. Na margem esquerda foram reconhecidos nove subsistemas, a maioria localizados em áreas do município de Macapá. Os seis subsistemas restantes estão em áreas do município de Santana. De acordo com Magalhães e Santos (2010), estas áreas úmidas são interconectadas com o canal principal da bacia hidrográfica do igarapé Fortaleza através de uma rede de drenagem dendrítica com canais meandrantes, visualizados nitidamente nas imagens de satélite dentro da planície de inundação.

Alguns sistemas de áreas úmidas da planície de inundação da bacia hidrográfica do Igarapé Fortaleza são interligados com os canais menores (canais de maré) que 
drenam a orla das cidades de Macapá e Santana. Na margem direita do igarapé da Fortaleza os subsistemas da planície de inundação se conectam com o canal das Pedrinhas e o canal Marina II que bordejam o Canal Norte do rio Amazonas. Na margem direita do igarapé de Fortaleza, na cidade de Santana, também se observa a conexão, no bairro do Provedor, com o canal do igarapé Princesa Isabel.

$\mathrm{Na}$ bacia do Canal do Jandiá e suas adjacências foram identificados dois sistemas de áreas úmidas com cobertura campestre associados ao Canal de Jandiá e no Lago da Vaca. A área ocupada por essas ressacas dentro dessas bacias equivale a $12,99 \%$ da área da bacia dessas redes de drenagem. Vale ressaltar, que apesar do sistema de área úmida do canal do Jandiá ser considerado com uma "ressaca", na realidade, se trata de mata ciliar alterada com a presença de uma vereda no interior.

Tais situações ocorrem, porque devido a dinâmica ambiental da região, florestas de várzea desmatadas, em algumas ocasiões podem apresentar padrões espectrais semelhantes aos sistemas da planície de inundação causando ambiguidades na interpretação. Estas ambiguidades podem ser minimizadas a partir da análise multitemporal de dados de sensores remotos e, dependendo do tempo da alteração, com levantamento de dados em campo.

\subsection{Variações Espaciais e Temporais das Inundações na Bacia do Igarapé Fortaleza}

A partir dos dados de observação da dinâmica das marés na bacia do igarapé Fortaleza foi possível delimitar as áreas onde os processos de cheias e de marés se superimpõem. A Figura 4 sumariza o quadro extremo de inundação para a região para o período chuvoso quando as águas das chuvas somam-se as águas das marés.

A influência das marés não foi detectada no ponto $M 01$, às proximidades da Lagoa dos Índios (M acapá), para os dois períodos analisados. Os maiores níveis de água foram registrados em maio de $2010 \mathrm{com}$ cerca de $3 \mathrm{~m}$ de altura. Os menores níveis de água ocorreram em novembro de 2009 que apresentou uma variação de 0,75 m no nível de água em relação ao período chuvoso (Figura 2B).

No ponto M 02, às proximidades do bairro do Zerão (Macapá), a influência das marés nas variações do nível de água são mais perceptíveis durante os meses de setembro e novembro, com amplitudes que chegam a 0,5 metros em novembro. Nos meses de março e maio, não foi observada a influência da onda da maré (Figura 2C). Curiosamente para este ponto a maior altura do nível de água foi observado, na sizígia de setembro de 2009, quando as alturas ultrapassaram os níveis do período chuvoso.

$\mathrm{Na}$ foz do igarapé Fortaleza a influência das marés é maior, traduzindo-se na presença de dois ciclos diários de marés bem definidos. As maiores amplitudes de marés ao longo do canal do Igarapé Fortaleza (em torno de 3 metros) foram encontradas nos meses de setembro e novembro (Figura 2D) fora do período chuvoso. Estas variações de marés comandam a situação de inundação no baixo 
curso do igarapé Fortaleza, adentrando pelos canais de ligação chegando facilmente aos sistemas de "ressacas".

Estes resultados demonstram que a influência dos processos de inundação por marés nas áreas úmidas da planície de inundação e dos diques marginais variam espacialmente dentro da bacia, porém aparentemente com maiores alturas do nível de água, no ponto M 02 no período seco. Tais situações deve ser melhor averiguadas com implantação de sistemas de coleta contínua de dados de forma automática, pois contradizem a situação de nível mais alto de água no período de inverno para este setor.

Em relação aos canais de marés, embora não tenha sido realizada nenhuma medição. Os relatos contínuos da defesa civil demonstrar que um dos canais, como 0 Canal Mendonça Jr. (Macapá), apesar de ser um canal retiticado, apresenta maiores efeitos de transbordamento em eventos de grandes inundações (superposição da dinâmica pluvial e dinâmica das marés), resultando em transtornos para a população e para o comércio local.

\subsection{Inundação nas Áreas Úmidas Costeiras Amazônicas e seus Desafios}

Diante dos resultados, que demonstram claramente na área urbana analisada, a influência dos processos climáticos e oceanográficos nas variações do nível de água, surge a necessidade de reconhecimento dos ciclos de inundação e seus processos. Estas informações são úteis para o zoneamento das áreas inundáveis, o que para Tucci (2004) passa prioritariamente pela determinação do risco das enchentes, mapeamento das áreas de inundação e realização do próprio zoneamento. No entanto, entre os dados necessários, para a elaboração desses produtos, o autor destaca a necessidade de: a) nivelamento de réguas em zero absoluto; b) topografia da cidade em mesmo referencial absoluto da régua limnimétrica e cotas dos locais a serem inundados. Esses desafios tecnológicos podem ser vencidos utilizando-se referenciais geodésico, tendo uma relação estreita com coleta de dados gravimétricos na região.

O baixo gradiente do relevo na região costeira amazônica impõe a necessidade de mapas topográficos em escalas mais adequadas para o mapeamento das inundações, quando se trata de áreas urbanas. Uma forma de gerar os mapas de relevo é o uso das geotecnologias espaciais. No entanto, tais técnicas possuem restrições devido a densa cobertura vegetal da região amazônica que interfere na geração de modelos digitais de terreno utilizando dados de sensores óticos clássicos que responde a altura do dossel.

Dados de sensores ativos, como o radar imageador seriam uma solução, mas devese atentar para a presença de umidade e espelhos de água no solo que não permitem o retorno do sinal emitido pelo radar ao sensor. No entanto, tal sensibilidade apresenta um potencial para a delimitação de corpos aquáticos (SILVA et al., 2011). 
Vale ressaltar que, menores comprimentos de onda do radar possuem restrições para detectar inundação sob regiões de cobertura florestal densa (SANTOS et al., 2009).

Reconhecer o nível da água sobre o terreno influenciado pelos vários fatores citados no item 2.2 exige também ações de monitoramento contínuo do nível das águas dos rios, em acoplamento com o nível das marés, para assim determinar com maior clareza o fenômeno de inundação nas áreas úmidas costeiras amazônicas, e gerar mapas de susceptibilidade à inundação de modo mais confiável.

Esse monitoramento passaria pela integração dos dados de nível das águas, com dados topográficos, em referenciais geodésicos únicos. No contexto do uso de dados de sensores remotos, o plano de referência é um modelo matemático associado ao elipsóide. Para os dados topográficos, tão necessários para estudar a dinâmica de inundação, os mesmos deveriam estar referenciados ao plano de referência do geóide que revela de certa forma está associado ao nível médio relativo do mar. Integrar esses dois modelos é necessário para que se possa conhecer a vulnerabilidade natural às inundações. Além do mais, é necessário integrar essas informações ainda com a topografia de fundo (batimetria). Tais investidas já foram feitas na região nordeste do Brasil (FERREIRA; AM ARO; SANTOS, 2014).

Enquanto esses desafios não são vencidos, métodos empíricos com utilização de dados de sensores remotos, mesmo com suas limitações (SANTOS, 2006), a exemplo do trabalho apresentado, podem auxiliar no mapeamento da dinâmica de inundação e sua variação espacial e temporal.

Vários países no mundo se preparam para o quadro de mudanças climáticas, que amplificarão os riscos costeiros, principalmente no que tange a intensificação dos problemas relacionados com a erosão e as inundações devido ao aumento contínuo do nível relativo do mar (IPCC, 2013). Este tambem é um dos desafios discutido no âmbito do Plano Nacional de Adaptação à Mudança do Clima (M MA, 2016), no capítulo de estratégias para as zonas costeiras, visto que a elevação do nível do mar e eventos extremos vai impactar os processos de inundação.

Este desafio deve ser considerado na perspectiva do gerenciamento costeiro integrado e essa preparação passa pela implantação, implementação e aumento da capacidade de monitoramento, resposta e mitigação dos eventos que podem se tornar catastróficos. Capacidade essa, intrinsecamente associada com uso de geotecnologias e integração entre as várias ciências e técnicas para dar as respostas necessárias para uso mais adequado do território.

Mazzorana et al. (2014) estabelecem os procedimentos básicos para determinar consistentemente as ameaças de inundação e os cenários de riscos. Dentre os principais passos, é necessária uma abordagem geomorfológica baseada na combinação de reconhecimento da morfologia dos vales, bacias de drenagem e, confinamento dos canais, por exemplo. Tais elementos não são possíveis de serem determinados, sem um mapeamento geomorfológico adequado e implantação de sistemas de monitoramento integrado do nível de águas que considerem os 
processos fluviais e oceanográficos, como é o caso das áreas úmidas no estado do Amapá.

No Brasil, ainda não existem sistemas de monitoramento integrados, cujos dados permitam mapear a extensão e o nível máximo de inundação, pois além de todo 0 instrumental necessário, é preciso definir procedimentos metodológicos adequados para a que os mapas de risco à inundação possam ser elaborados, considerando as consequências potencialmente adversas nos diferentes cenários de inundação.

\section{CONSIDERAÇÕES FINAIS}

Os resultados deste trabalho permitiu redefinir os limites da bacia hidrográfica do Igarapé Fortaleza e determinar suas conexões com outras redes de drenagens locais. Os sistemas de áreas úmidas da planície de inundação, denominados localmente de "ressacas", interligam-se com o Rio Amazonas, não apenas pelo canal do igarapé Fortaleza, mas também por alguns canais que ocorrem ao longo da Orla de Macapá e Santana.

Os resultados demonstram claramente que o nível de inundação nas áreas úmidas urbanas de Macapá e Santana é interdependente dos processos climáticos globais, regionais e os oceanográficos, evidenciados pelas variações sazonais do nível dos rios, variações semidiurnas e sazonais do nível das marés.

As marés observadas se encontram na faixa de mesomarés, para o baixo curso do igarapé Fortaleza, cuja influência decresce em direção a montante deste curso, até as proximidades da Lagoa dos Índios, quando os sistemas aparentemente não possuem mais a influência das marés. Assim, os sistemas identificados podem ser classificados como áreas úmidas costeiras (coastal wetlands) o que traz implicações de ordem metodológica para os estudos de inundação, uma das informações necessárias para definir estratégia de adaptação às mudanças do clima.

As informações coletadas, ainda não permitem falar da magnitude dos processos de inundação, no entanto indica um procedimento metodológico que deveria ser adaptado, aprimorado e automatizado com melhoramento dos processos de coleta dos dados sobre as variações no nível de água, cujas informações podem ser correlacionadas com dados topográficos, em referencial geodésico único. Estas informações integradas com dados socioeconômicos adequados permitirão definir a vulnerabilidade e riscos a inundação nas áreas úmidas identificadas.

Diante do cenário de mudanças climáticas previstas no mundo, um significante impacto sobre as áreas úmidas costeiras é esperado, aumentando os riscos associados aos fenômenos de erosão e de inundação. A magnitude desses impactos é incerta e sua influência no processo de ocupação, uso do território e geração de danos ambientais e socioeconômicos nas zonas costeiras ainda é pouco avaliada. Este desafio deve ser enfrentado de forma séria, implementando-se sistemas de monitoramento integrando os sistemas fluviais e costeiros, de forma a garantir 
melhores informações para pautar as estratégias de prevenção e mitigação de impactos.

\section{Agradecimentos}

Agradecemos a equipe do Núcleo de Pesquisas Aquáticas (estagiários, bolsistas e técnicos) pelo auxílio na coleta de dados de campo. Ao Laboratório de Sensoriamento Remoto e Análises Espaciais Aplicado a Ambientes Costeiros (LASA), Núcleo de Pesquisas Aquáticas (NuPAq/IEPA) pela cessão da infraestrutura. Ao Instituto Nacional de Reforma Agrária (INCRA/AP), Instituto de Meio Ambiente do Amapá-AP (IMAP) e Secretaria de Estado de Meio Ambienta (SEMA) pela cessão de equipamentos e auxílio na coleta de dados de DGPS. Rede 05-PETROMAR N/NE, Fundo Setorial CT-Petro, pelos insumos utilizados nas atividades de campo e ao Ministério Público do Amapá (MP/AP) pelo financiamento do Projeto Zoneamento Ecológico-Econômico Urbano das Áreas de Ressacas de Macapá e Santana, Estado do Amapá. Aos revisores pelas correções e sugestões.

\section{REFERÊNCIAS}

ANA - AGÊNCIA NACIONAL DE ÁGUAS. Mapa da Região Hidrográfica Amazônica, escala 1:3.500.000. Brasília: SGI. 2006. Disponível em http://www2.ana.gov.brPaginas / portais/bacias/amazonica.aspx. Acesso em: 10 Out 2016.

ALMEIDA. Edson de Faria. Sensibilidade ambiental a derramamentos de óleo dos ecossistemas costeiros da região do Cabo Norte, Amapá: A contribuição do sensoriamento remoto. Tese (Doutorado em Engenharia) - Universidade Federal do Rio de Janeiro, Rio de Janeiro, 2008. 202p

AMAPÁ. Lei número 0455, de 22 de julho de 1999. Dispõe sobre a delimitação e tombamento das áreas de "ressacas" localizadas no estado do Amapá e dá outras providências. Macapá: Diário Oficial do Estado do Amapá, 1999.

BAKER, Victor. Fluvial landforms. Goddard Earth Sciences. 2009. Disponível em: বttp://disc.sci.gsfc.nasa.gov/geomorphology/geo_4>. Acesso em: 30 Jul 2011. BLOOM, Arthur. Geomorphologhy. 3rd. Illinois:Waveland Press, Inc, 2004. 482p. BRASIL. Lei número 9.433, de 8 de janeiro de 1997. Instituti a Política e o Sistema Nacional de Gerenciamento de Recursos Hídricos. Diário Oficial da União, 1997.

COLLINSON, John. D. Alluvial sediments. In: READING, Harold. G. Sedimentary environments: processes, facies and stratigraphy. Oxford: BackwellScience Ltd., 2012. p.37-82.

COSTA, Heide Keller Sales, SANTOS, Valdenira Ferreira. Estudo da dinâmica de inundação das áreas de ressacas. In: TAKIYAMA, Luis Roberto, SILVA, Uédio Robds Leite da, JIMENEZ, Érica Antunes, PEREIRA, Ronaldo Almeida, ZACARDI, Diego Maia, FERNANDES, Erlyson Farias, SOUTO, Flávio Augusto França, SILVA, Luis Maurício 
Abdon da, SILVA, Márcio Sousa da, SANTOS, Maria Aparecida Corrêa dos, COSTA NETO, Salustiano Vilar da, SANTOS, Valdenira Ferreira dos. Projeto zoneamento ecológico-econômico urbano das áreas de ressacas de Macapá e Santana, Estado do Amapá. Macapá: IEPA. 17 p., 2012.

FERREIRA, Anderson Targino, AM ARO, Venerando Eustaquio, SANTOS, Marcelo Teles. Geodésia aplicada à integração de dados topográficos e batimétricos na caracterização de superfícies de praia. Revista Brasileira de Cartografia, v. 66, n.1, p. 167-184. 2014.

GRATIOT, Nicolas, ANTHONY, Edward, GARDEL, Antoine, GAUCHEREL, Cedric, PROISY, Christophe, WELLS, John T. Significant contribution of the 18.6 year tidal cycle to regional coastal changes. Nature Geoscience. v. 1, p. 169-172, 2008.

HESS, Laura L., MELACK, John M., NOVO, Evlyn M. L. M., BARBOSA, Claudio, C. F., GASTIL, Mary. Dual-season mapping of wetland inundation and vegetation for the central Amazon basin. Remote Sensing of Environment, v. 87, p. 404-428, 2003.

IBGE - INSTITUTO BRASILEIRO DE GEOGRAFIA E ESTATÍSTICA. Modelo de ondulação geoidal - MAPGEO2004. 2004. Disponível em http://www.ibge. gov.br/seminario_re ferencial_geocentrico/. Acesso em: 30 Jul 2011.

IUCN - INTERNATIONAL UNION FOR CONSERVATION OF NATURE. The Ramsar Conference: Final act of the international conference on the conservation of wetlands and waterfowl, IUCN, Bulletin n. 2. Annex 1.Special Supplement, 4p., 1971.

IPCC - INTERGOVERNM ENTAL PANEL ON CLIMATE CHANGE. Summary for policymakers. In: Stocker et al (eds.). Climate Change 2013: The Physical Science Basis. Contribution of Working Group I to the Fifth Assessment Report of the Intergovernmental Panel on Climate Change. Cambridge: Cambridge University Press, 2013.

LATRUBESSE, Edgardo M.; STEVAUX, José Cândido; SINHA, Rajiv. Tropical rivers. Geomorphology, v. 70, p. 187-206, 2005.

LOINTIER, Marc. Hydrologie des zones humides tropicales apport de I'information spatialisée aux problèmes de gestion intégrée: aplications en Guyane. Tese (Doutorado em Ciências da Terra) - Université Peirre et Marie Curie, Paris VI, Paris, 231 p., 1996.

MACIEL, Norma. Ressaca: ecossistema úmido costeiro do estado do Amapá. diagnóstico preliminar. Propostas de recuperação, preservação e uso sustentado. M acapá: SEM A, 253p., 2001.

MAGALHÃES, Carliendel Dias; SANTOS, Valdenira Ferreira. Análise da rede de drenagem da bacia hidrográfica do igarapé da fortaleza utilizando imagens de alta resolução. Relatório de Bolsa do Programa de Bolsa em Iniciação Científica. Macapá: PIBIC/CNPq/IEPA. 2010.

MARTINEZ, Jean-Michel; Le-TOAN, Thuy. Mapping of flood dynamics and spatial distribution of vegetation in the Amazon floodplain using multitemporal SAR data. Remote Sensing of Environment. n.108, p. 209-223, 2007. 
MAZZORANA, Bruno, SIMONI, S., SCHERER, C., GEMS, B., FUCHS, S., KEILER, M. A physical approach on flood risk vulnerability of buildings, Hydrol. Earth Syst. Sci., v. 18, p. 3817-3836, 2014.

MMA - MINISTÉRIO DO MEIO AM BIENTE. Plano Nacional de Adaptação à Mudança do Clima: estratégias setoriais e temáticas. Vol. 2. Brasília: M M A, 2016.

MITSCH, William J. (ed.). Global wetlands: old world and new. Amsterdam: Elsevier Science, 992p., 1994.

PEREIRA, Ronaldo Almeida. Expansão e planejamento urbano em Macapá. o caso da Gleba Infraero. 2013. 154 f. Trabalho de conclusão de Curso (Graduação em Arquitetura e Urbanismo) - Universidade Federal do Amapá, Santana, 2013.

PERILLO, Gerardo M.E. Tidal courses: classification, origin and functionality. In: PERILLO, Gerardo M. E. et al. (eds). Coastal wetlands: an integrated ecosystem approach. Elsevier, 2009, $185 \mathrm{p}$.

PRIGENT, Catherine, MATTHEWS, Elaine, AIRES, Felipe, ROSSOW, William B. Remote sensing of global wetland dynamics with multiple satellite data sets. Geophysical Research Letters, v. 28, p.4631-4663, 2001. Disponível em http://www.Imd.jussier.fe/ falmd/articles/2001_PrigentM atthews.pdf. Acesso em: 30 Jun 2015.

RABUS, Bernhard, EINDER, Michael, ROTH, Achim, BAMLER, Richard. The shuttle radar topography mission: a new class of digital elevation models acquired by spaceborne radar. Journal of Photogrammetry \& Remote Sensing, n.57, p. 241-262, 2003.

RICHEY, Jeffrey E.; NOBRE, Carlos; DESER, Clara. Amazon river discharge and climate variability: 1903 to 1985. Science, v. 246, p. 101-103, 1989.

ROSS, David A. Introduction to oceanography. New York, NY: HarperCollins. p. 236242. 1995.

SANTOS, Afonso de Paula dos. Avaliação da acurácia posicional em dados espaciais com o uso de estatística espacial. 2010. 110 f. Dissertação (M estrado em Engenharia Civil) - Universidade Federal de Viçosa, Viçosa, 2010.

SANTOS, Valdenira Ferreira. Ambientes costeiros amazônicos: avaliação de modificações ambientais por sensoriamento remoto. 2006. $306 \mathrm{f}$. Tese (Doutorado em Geologia e Geofísica Marinha) - Universidade Federal Fluminense, Niterói, 2006.

SANTOS, Valdenira Ferreira, MENDES, Amilcar, SILVEIRA, O. F. M. (in memoriam), PROST, Catherine, JIMENEZ, Erica Antunes, TAKIYAMA, Luis Roberto, FIGUEIRA, Zanandrea Ramos. (orgs.). Atlas de sensibilidade ambiental ao óleo da Bacia da Foz do Amazonas. Macapá: IEPA, 2016. 104p.

SANTOS, Valdenira Ferreira; ANDRADE, Ana Cláudia da Silva; SILVEIRA, Odete de Fátima Machado da; MARTINS, Marcos Henrique de Abreu; CARVALHO, Fábio Pinto de. Dinâmica Geomorfológica. In: SANTOS, Valdenira Ferreira; FIGUEIRA, Zanandrea Ramos (orgs.). Zoneamento Ecológico-Econômico do setor costeiro estuarino: fase diagnóstico socioambiental. Macapá: IEPA/GERCO, 2004. Disponível em http://www. 
iepa.ap.gov.br/estuario/arq_pdf/vol_1/cap_3_dinamica_geomorfologica_atualz.pdf. Acesso em: 15 Jun 2011.

SANTOS, Valdenira Ferreira; POLIDORI, Laurent; SILVEIRA, Odete de Fátima Machado da; FIGUEIREDO JR, Alberto Garcia de. Aplicação de dados multisensor (SAR e ETM +) no reconhecimento de padrões de uso e ocupação do solo em costas tropicais: Costa Amazônica, Amapá, Brasil. Revista Brasileira de Geofísica, São Paulo, v. 27, supl. 1, p. 39-55, 2009.

SANTOS, Valdenira Ferreira et al. Geologia da Planície Costeira Estuarina, AmapáNorte do Brasil. In: Simpósio de Geologia Da Amazônia, 8, 2001. Anais... Belém: SBG, 2001.

SANTOS, Valdenira Ferreira; FIGUEIREDO JR, Alberto Garcia de; SILVEIRA, Odete de Fátima Machado da; POLIDORI, Laurent. The ENSO influence on the Amazonian Coastal Plain, Brazil. In: The Meeting of the Americas., Abstracts Foz do Iguaçu: AGU, 2010.

SANTOS, Valdenira Ferreira; FIGUEIRA, Zanandrea Ramos. Considerações iniciais sobre o meio socioeconômico do Setor Costeiro Estuarino. In: SANTOS, Valdenira Ferreira; FIGUEIRA, Zanandrea Ramos (orgs.). Zoneamento Ecológico-Econômico do setor costeiro estuarino. fase diagnóstico socioambiental. Vol. 2. Macapá: IEPA/GERCO, 2004. Disponível em http://www.iepa.ap.gov.br/estuario/arq_pdf/ vol_2/cap_1_consideracoes_iniciais_socio.pdf. Acesso em: 15 Jun 2011.

SCHUM M, Stanley Alfred. The fluvial system. New Jersey: The Blackburn Press, 2003. SILVA, Isabela Habib Canaan da, BEISL, Carlos Henrique, MIRANDA, Fernando Pellon, LANDAU, Luiz. Uso de radar orbital para a caracterização espaço-temporal do fenômeno de inundação em Villahermosa, México. In: Simpósio Brasileiro de Sensoriamento Remoto, 5., Curitiba. Anais... Curitiba: SBSR, 2011, p.5239-5346.

SILVEIRA, André L. L. Ciclo hidrológico e bacia hidrográfica. In: TUCCI, Carlos Eduardo M orelli (Org). Hidrologia: ciência e aplicação. 3a ed. Porto Alegre: EFRGS, 2004. p. 3551.

SOARES, Paulo C., FIORI, Alberto P. Lógica e sistemática na análise e interpretação de fotografias aéreas em geologia. Not. Geomorfol., v. 16, n. 32, p 71-104, 1976.

TAKIYAMA, Luis Roberto, SILVA, Uédio Robds Leite da, JIMENEZ, Érica Antunes, PEREIRA, Ronaldo Almeida, ZACARDI, Diego Maia, FERNANDES, Erlyson Farias, SOUTO, Flávio Augusto França, SILVA, Luis Maurício Abdon da, SILVA, Márcio Sousa da, SANTOS, Maria Aparecida Corrêa dos, COSTA NETO, Salustiano Vilar da, SANTOS, Valdenira Ferreira dos. Projeto Zoneamento Ecológico-Econômico urbano das áreas de ressacas de Macapá e Santana, estado do Amapá. Relatório Técnico Final. Macapa: IEPA, 84p., 2012. Disponível em http://www.mpap.mp.br/images/PRODE M AC/livros/Livro\%20Ressacas.pdf. Acesso em: 25 Out 2016.

TOLEDO, Mauro B. e BUSH, Mark B. A Holocene pollen record of savanna establishment in coastal Amapá. An. Acad. Bras. Ciênc. Rio de Janeiro, vol. 80, n. 2, p. , 2004. 
TUCCI, Carlos Eduardo Morelli. Escoamento Superficial. In: TUCCI, Carlos Eduardo Morelli. (Org). Hidrologia: ciência e aplicação. 3a ed. Porto Alegre, EFRGS, 2004. p.391-441.

Artigo recebido em 25 de outubro de 2016.

Aprovado em 04 de novembro de 2016. 